\title{
EMBODIED ENERGY ANALYSIS OF NEW ZEALAND POWER GENERATION SYSTEMS
}

\author{
Deshan Fernando, Pat Bodger \\ Department of Electrical and Computer Engineering, University of Canterbury \\ Private Bag 4800, Christchurch, New Zealand \\ deshan_f@hotmail.com, pat.bodger@canterbury.ac.nz
}

\begin{abstract}
Embodied energy is the energy consumed in all activities necessary to support a process in its entire lifecycle. For power generation systems, this includes the energy cost of raw material extraction, plant construction, operation and maintenance, and recycling and disposal. Embodied energy analysis is a crude method of estimating the environmental impacts and depletion of natural resources consequent to a certain process. In effect, the higher the embodied energy of a process, the greater the green house gas emissions and the depletion of natural resources.

This paper presents the embodied energy analysis carried out on some New Zealand power plants belonging to various methods of generation. The analysis follows the standards set out by the International Organisation for Standardisation 14040 series, and uses some guidelines given in the International Federation of Institutes for Advanced Study workshop on energy analysis methodology and conventions. It was found that the lifecycle performance, in terms of energy payback, of renewable electricity generation is superior to nonrenewable electricity generation. From the generation methodologies, hydro power plants have exceptional performance characteristics.
\end{abstract}

\section{KEY WORDS}

Embodied Energy, Environmental Impacts, Power Generation

\section{Introduction}

Since industrialisation, combustion of fossil fuels has dominated the global energy market to meet the ever increasing demands for heat, electricity and transportation. The combustion of fossil fuels releases green house gases (GHGs) such as carbon dioxide, methane and nitrous oxides into the earth's atmosphere. This has led to the release of large quantities of GHGs into the earth's atmosphere. The high rates of anthropogenic GHG emissions have resulted in an enhanced natural greenhouse effect which has led to an increase in the earth's surface temperature, known as anthropogenic global warming.

Until recently, decisions on which electrical generation systems are to be utilised were made purely based on the monetary cost of building the generation station, operating and maintaining it, and disposing of it. However, since it has been revealed that the rate of fossil fuel and natural gas consumption leads to the exhaustion of these resources in the future [1], scientists and engineers have carried out more detailed investigations on renewable energy sources that were not widely used, such as wind energy and solar energy. Previously, thorough investigations were not carried out on these resources because, the starting up costs of these types of power plants were high, there was lack of awareness of environmental damage caused by the consumption of fossil fuels and natural gas, and fossil fuels were available in vast amounts.

Embodied energy is the energy consumed in all activities necessary to support a process [2]. For power generation systems, this includes the energy cost of the entire lifecycle process chain; raw materials extraction and transportation, plant construction, energy generation, and the recycling and disposal stages following actual use [3]. Although a crude method, embodied energy analysis can be used to estimate the environmental impacts and the depletion of natural resources. Broadly speaking, the higher the use of energy, the greater the GHG emissions, hence the greater the effect on the environment, and the greater the depletion of natural resources [4].

Embodied energy analysis can provide decision makers with a better understanding of the environmental impacts and natural resource depletion associated with each alternative. Also, it can give insight as to which stages of different system development alternatives result in major impacts and thus help decisions in the various stages of the electricity generation life cycle in energy conservation [3]. Also, with respect to decision-making, embodied energy analysis is a useful complement to conventional economic analysis. It can provide additional information on which to base energy resource allocations. 
Furthermore, the combined use of energy analysis with economic evaluation can correct implicit errors in economic analysis that can lead to the misallocation of resources [5].

The aim of this study was to calculate the embodied energy of some New Zealand power plants belonging to various methods of generation, which may influence the decision making process of future investments in the New Zealand electricity generation industry. Embodied energy analysis is undertaken on natural gas combined cycle (NGCC), natural gas open cycle (NGOC), wind, reservoir hydro and run of river hydro generation systems.

\section{Embodied Energy Analysis Methodology}

The fundamental methods for embodied energy analysis can be classified as input-output (I/O) analysis and process chain analysis (PCA). I/O analysis employs the economic input-output tables of a nation's economy [6]. The input-output tables are an economic tool used to examine dollar flows between sectors of a national economy. Statistics NZ publishes these results approximately every five years. The I/O method correlates dollar cost to energy consumption, by examining the dollar flows to and from the energyproducing sectors of the economy and compares these with the known amount of energy produced by each energy sector. This makes it possible to trace the energy flows within the national economy and to equate the dollar output of each sector with its energy usage. The main advantage of I/O analysis is that every energy transaction across the entire national economy is captured. The principal disadvantage is that the results are less specific and hence less accurate for the study concerned [7].

In PCA, each material that makes up the final system is traced back through each manufacturing process to it's initial extraction [8]. PCA normally begins with the final production process and works backwards through each stage of the production process. It is the most common method of energy analysis. This is because the data required can usually be obtained. The main advantage of PCA is that it produces accurate and specific results, while the main disadvantage is that it requires a considerable amount of time and effort [7]. However, the almost infinite inflows into the process means that a large number of energy inputs to the process are not calculated and the analysis has to be terminated at a point where the input is believed to add a negligible amount to the total energy use [9]. Therefore, PCA tends to underestimate the total embodied energy of a process.

When carrying out embodied energy analysis, either International Federation of Institutes for Advanced Study (IFIAS) standards or International Organisation for Standardisation (ISO) 14040 series can be used [10], [11-
14]. The ISO standards give generic guidelines for any lifecycle assessment (LCA), whereas the IFIAS standards focus specifically on energy analysis methodology and conventions. The analysis was carried out using a combination of both I/O analysis and PCA. It follows the standards set out by the ISO 14040 series, whilst also using some useful guidelines set out in the IFIAS standards.

The three main phases of the ISO standards are goal and scope definition, inventory analysis, and impact assessment and interpretation. The goal of this paper is to calculate the embodied energy of some New Zealand power plants belonging to various methods of generation, as a mean of comparing the different methods of generation, and to give decision makers a better understanding of the energy intensity of the different generation methods and the various phases in their lifecycles. The scope includes elements specific to the plant studied, such as data requirements, assumptions, system boundaries and allocation procedures.

An important element that is mentioned in the scope of study in the ISO standards is the functional unit. The functional unit is stated as "a measure of the performance of the functional outputs of the product system". The primary purpose of a functional unit is to provide a reference to which the inputs and outputs are related [11]. The functional unit for this study is the unit amount of electricity produced (i.e. $\mathrm{kWh}$ ).

The other phases of LCA, according to the ISO standards, are impact assessment and interpretation. The impact assessment phase of LCA is aimed at evaluating the significance of potential environmental impacts using the results of the life cycle inventory analysis [11]. Embodied energy analysis is a crude method of evaluating environmental impacts, as mentioned previously. Hence, evaluating the embodied energy is inclusive of impact assessment. As for interpretation, the performances of different methods of generation are compared using the lifecycle energy payback ratio (LEPR) and the lifecycle energy cost (LEC) of the power plants stated in Equations (1) and (2), respectively.

$$
\begin{aligned}
& L E P R=\frac{\text { Lifecycle Electrical Output }(\text { in GJ) }}{\text { Lifecycle Energy Input }(\text { in } G J)} \\
& L E C=\frac{\text { Lifecycle Energy Input }(\text { in } M J)}{\text { Lifecycle Electrical Output (in } k W h)}
\end{aligned}
$$




\section{Embodied Energy Analysis of Specific Plants}

\subsection{NGCC Power Plant}

The NGCC power plant, used for the embodied energy analysis in this paper, is located at Huntly power station in the North Island, owned and operated by Genesis Energy Ltd. It was commissioned in June 2007. The Huntly power station consists of three separate generation plants. They are a coal and gas fired steam plant, an NGOC plant and an NGCC plant [15]. Each of the generation plants is segregated and the operation of one plant does not affect the operation of another. Hence, embodied energy analysis can be carried out on all three plants as separate entities.

The lifecycle of an NGCC plant consists of plant construction (which includes plant equipment), natural gas exploration, production and transmission (fuel cycle), plant operation, and plant decommissioning and land reclamation. The useful product is the electrical energy generated by the plant.

The Huntly NGCC unit has a capacity of 385 MW. It has a capacity factor of $86 \%$, which means it generates at full capacity for $86 \%$ of the calendar year, and a net thermal efficiency of 57\% [16], [17]. Over its assumed useful life of 40 years, the Huntly NGCC unit produces 116,000 GWh of useful electricity. The lifecycle energy input, or the embodied energy, of the Huntly NGCC power plant is $8.57 \times 10^{8} \mathrm{GJ}$.

\subsection{NGOC Power Plant}

The NGOC power plant used for the analysis in this paper, located at Huntly power station, is also owned and operated by Genesis Energy Ltd. It was commissioned in June 2004. The lifecycle of the NGOC power plant is equivalent to that of the NGCC power plant. The total capacity of the Huntly NGOC unit is $48 \mathrm{MW}$. It has a capacity factor of $78 \%$ and a net thermal efficiency of $21 \%$ [18], [19]. The useful electrical output of the Huntly NGOC unit, over its assumed life of 40 years, is 13,100 GWh. The lifecycle energy input, or the embodied energy of the Huntly NGOC unit is $1.34 \times 10^{8}$ GJ.

\subsection{Wind Farm}

The embodied energy analysis of wind generation was based on the White Hill wind farm, owned and operated by Meridian Energy Ltd. It is located in the south of the South Island. It started producing electricity on the $8^{\text {th }}$ of June 2007. The White Hill wind farm contains 29, 2MW wind turbines, and hence has a total capacity of 58MW. The wind turbines are V80 turbines manufactured by Vestas, a Danish wind turbine manufacturing company [20],[21].The life cycle of a wind farm consists of turbine production, turbine transportation to site, site construction (which includes wind farm fixed assets), wind farm operation and maintenance, and dismantling, scrapping and land reclamation.

The useful life of the White Hill wind farm was assumed to be 20 years, which is the life of the Vestas V80 wind turbines. The availability factor of the turbines was assumed to be $90 \%$, which means each turbine generates electricity for $90 \%$ of the calendar year. This availability factor takes into consideration that the turbines only operate under certain wind speeds, which are $4-25 \mathrm{~m} / \mathrm{s}$ $(14.4-90 \mathrm{kph})$ for wind turbines at the White Hill wind farm. Within this range, the turbines can only generate electricity at full generation capacity at a nominal speed of $15 \mathrm{~m} / \mathrm{s}$. This is accounted for by the annual plant factor of $45 \%$, which corresponds to the ratio of actual generation to that of generation at full capacity [20], [22]. The total useful electrical output of the wind farm was calculated to be 4,120 GWh. The lifecycle energy input, or the embodied energy of the wind farm was estimated to be $1.86 \times 10^{6} \mathrm{GJ}$.

The recycling and scrapping of the Vestas V80 wind turbines has a negative embodied energy [23]. This represents an energy gain because of the lower energy embodied in recycling the materials when compared to the extraction of the materials in their raw state from the earth, for future use. It was assumed that the energy embodied in the other stages of plant decommissioning (e.g. plant equipment dismantling) cancels out with the energy gain in recycling of turbine materials. Therefore, the energy embodied in White Hill wind farm decommissioning was assumed to be zero. The land reclamation embodied energy was also assumed to be negligible, as the land a wind farm operates on can be used for other purposes, such as farming, while the wind farm is in operation [20].

\subsection{Reservoir Hydro Power Plant}

The embodied energy analysis for a reservoir hydro power station is based on the Benmore power station, on the Waitaki River located in the south central region of the South Island. It is owned and operated by Meridian Energy Ltd and has a capacity of 540 MW. The construction work for Benmore power station began in 1958 and the first electricity was generated in January 1965 [24], [25].

The lifecycle of a reservoir hydro power station consists of preliminary investigations and river diversion, power plant construction and civil works, operation and maintenance, and plant decommissioning and land reclamation. For the Benmore power station, the power plant construction and civil works include the hydro dam, the spillway, the intake and penstocks, and the power house and switchyard. 
The lifecycle electrical energy output of the Benmore power station was estimated by multiplying the average annual energy output to the national system by the estimated life of the Benmore power station. The average annual electrical energy output of Benmore power station is 2,215 GWh [24]. The total life of the Benmore power station was assumed to be 200 years, as it has already been in operation for 45 years and Meridian Energy has predicted it will be in operation for more than another 145 years [26]. The total lifecycle electrical output was estimated to be 443,000 GWh. The lifecycle energy input, or the embodied energy of the Benmore power station is $2.54 \times 10^{7} \mathrm{GJ}$.

\subsection{Run of River Hydro Power Plant}

The embodied energy analysis for run of river hydro generation is based on the Aratiatia power station, on the Waikato River in the central North Island, owned and operated by Mighty River Power Ltd. It contains three 31.3 MW vertical Francis turbines and three 30MW generators. The turbines never achieve the designed total output capacity of $90 \mathrm{MW}$. The generators at Aratiatia were commissioned in 1964 [27],[28].

The lifecycle of a run of river hydro power plant consists of preliminary investigations and river diversion, power plant construction and civil works, operation and maintenance, and decommissioning and land reclamation. For the Aratiatia power station, power plant construction and civil works include the intake tunnel, surge tank, spillway, penstocks, powerhouse and switchyard, and the control gates.

The lifecycle electrical energy output of Aratiatia power station was estimated by multiplying the annual electrical energy output to the national grid by the estimated life of the Aratiatia power station. The average annual electrical energy output of the Aratiatia power station to the national grid is $270 \mathrm{GWh}$ [28]. The useful life of Aratiatia power station was assumed to be 200 years. The total lifecycle electrical output was estimated to be 54,000 GWh. The lifecycle energy input, or the embodied energy, of the Aratiatia power station is $2.01 \times 10^{6} \mathrm{GJ}$.

\section{Results and Discussion}

In order to compare the embodied energies of the various lifecycle phases among the different generation methods, the lifecycles of the various plants are divided into three main sections. They are exploration and plant construction, plant operation and maintenance, and plant decommissioning and land reclamation.

\subsection{Exploration and Plant Construction}

The embodied energy normalised per unit of lifecycle electrical energy output, the functional unit, and the proportions of the total embodied energy in the exploration and plant construction phase of the lifecycle, for the different types of generation stations, are shown in Figures 1 and 2, respectively.

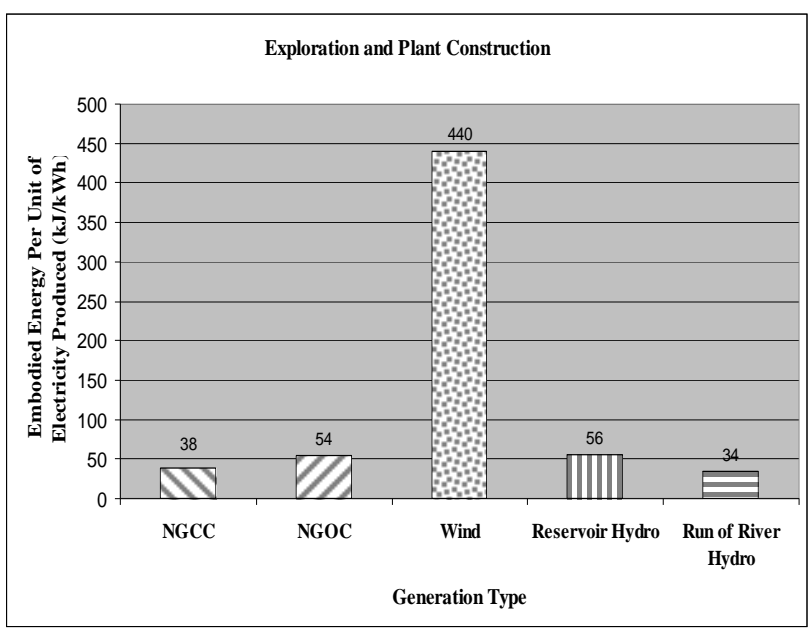

Fig. 1. Normalised Embodied Energies of Exploration and Plant Construction for the Different Generation Methodologies

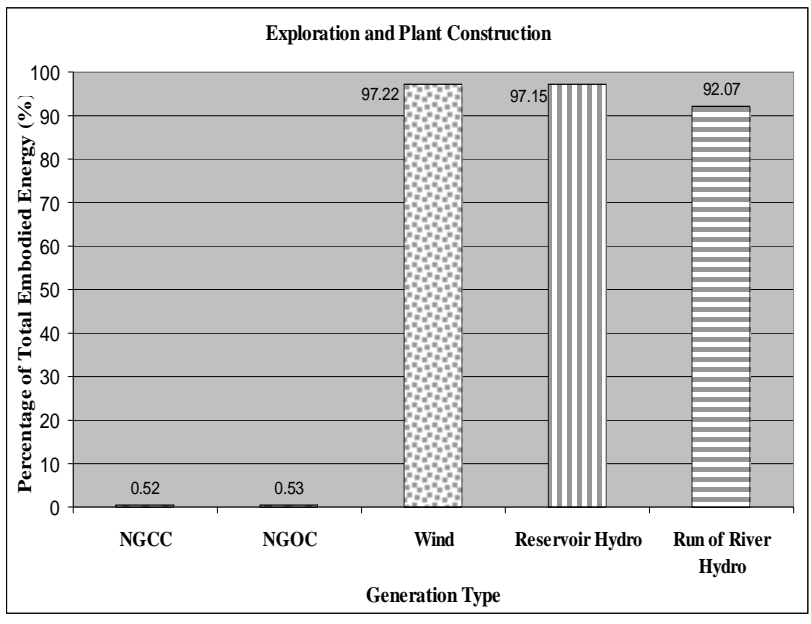

Fig. 2. Proportion of Total Embodied Energy in Exploration and Plant Construction for the Different Generation Methodologies

The wind farm has the highest amount of normalised energy embodied in exploration and plant construction, being $440 \mathrm{~kJ} / \mathrm{kWh}$, followed by that for reservoir hydro and NGOC power plants at $56 \mathrm{~kJ} / \mathrm{kWh}$ and $54 \mathrm{~kJ} / \mathrm{kWh}$ respectively. The significant difference between the value for the wind farm and the other power plants can be attributed to the lower power rating and smaller life of the wind farm when compared to the high measures of energy embodied in constructing the wind turbines.

The reservoir hydro power plant is ranked second. Its value is significantly lower than that of the wind farm because of it's longer useful life and the higher rating of the power plant. However, the value for the reservoir hydro power plant was larger than the non-renewable power plants due to the large quantity of energy embodied in the construction of the hydro dam. The value for the NGCC power plant is lower than that of the NGOC power 
plant because of the higher thermal efficiency of the NGCC power plant.

The run of river hydro power plant has the lowest value, even though its power rating is much lower than the reservoir hydro and the NGCC power plants. This is because its useful life is equivalent to that of the reservoir hydro power plant, and because a major energy expenditure is avoided by not constructing a hydro dam.

The energy embodied in exploration and plant construction accounted for $97.22 \%$ of the total embodied energy, for wind generation. For the hydro power stations, the proportions were very high at $97.15 \%$ and $92.07 \%$ for the reservoir and run of river hydro power stations, respectively. For the NGCC and NGOC power plants, the proportions are $0.52 \%$ and $0.53 \%$. Therefore, exploration and construction accounts for a large portion of the total embodied energy in renewable generation, whereas in non-renewable generation it is insignificant.

\subsection{Plant Operation and Maintenance}

The embodied energy normalised per unit of lifecycle electrical output and the proportions of the total embodied energy, in plant operation and maintenance, for the different types of generation stations, are shown in Figures 3 and 4, respectively. The NGOC power plant has the highest value of $10,112 \mathrm{~kJ} / \mathrm{kWh}$, followed by that for the NGCC power plant at $7,346 \mathrm{~kJ} / \mathrm{kWh}$. The value for the NGOC plant is higher than that of the NGCC plant, because the NGOC power plant has a lower thermal efficiency than the NGCC plant.

The value for the wind farm, at $13 \mathrm{~kJ} / \mathrm{kWh}$, followed the non-renewable power plants. It is notably higher than that of the hydro power plants due to the lower power rating and shorter life of the wind farm, compared to the hydro power plants. This could also be due to the high maintenance cost of the wind turbines due to their lower operational reliability.

Plant operation and maintenance accounted for nearly $99.5 \%$ of the total embodied energy for both the nonrenewable plants. For the renewable power plants, however, plant operation and maintenance accounted for very small proportions of the plants' total embodied energy, the highest being about 5\% for the run of river hydro power station. The normalised plant operation and maintenance embodied energy and the proportion of total embodied energy in plant operation and maintenance are much larger in non-renewable power plants due to the large measures of energy embodied in their fuel input.

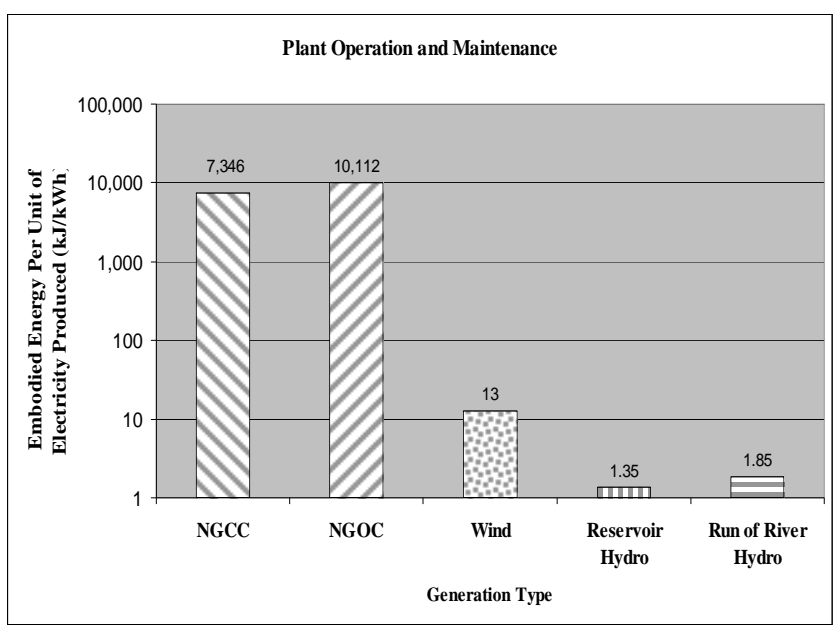

Fig. 3. Normalised Embodied Energies of Plant Operation and Maintenance for the Different Generation Methodologies

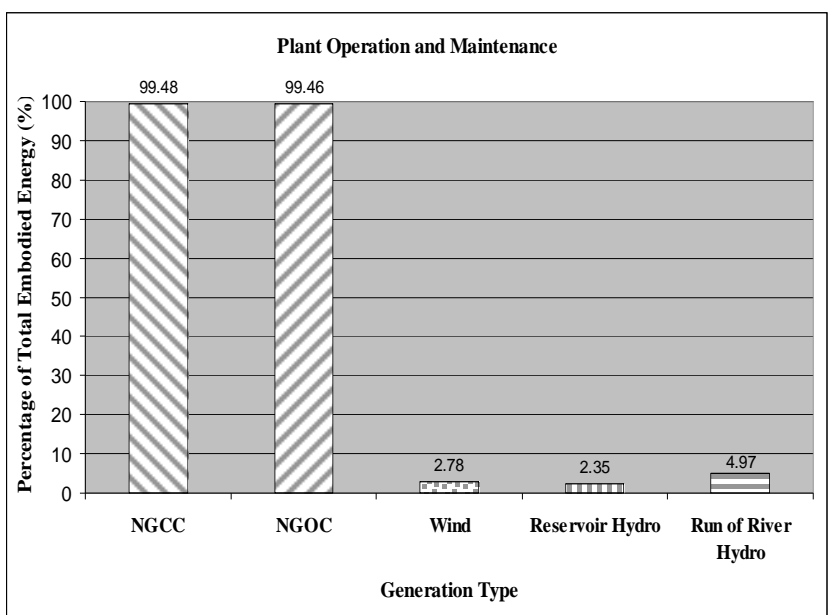

Fig. 4. Proportion of Total Embodied Energy in Plant Operation and Maintenance for the Different Generation Methodologies

\subsection{Plant Decommissioning and Land Reclamation}

The embodied energy normalised per unit of lifecycle electrical output and the proportions of the total embodied energy in plant decommissioning and land reclamation, for the different types of generation stations, are shown in Figures 5 and 6, respectively.

Both the normalised embodied energy and the proportion of total embodied energy in plant decommissioning and land reclamation were larger for the hydro power stations. This is because of the larger scale of construction involved in the hydro plants, which means that decommissioning would require more energy than the other power plants. The higher proportion of the run of river hydro power plant reflects the fact that decommissioning of a reservoir hydro power plant would not involve the complete removal of the hydro dam. 


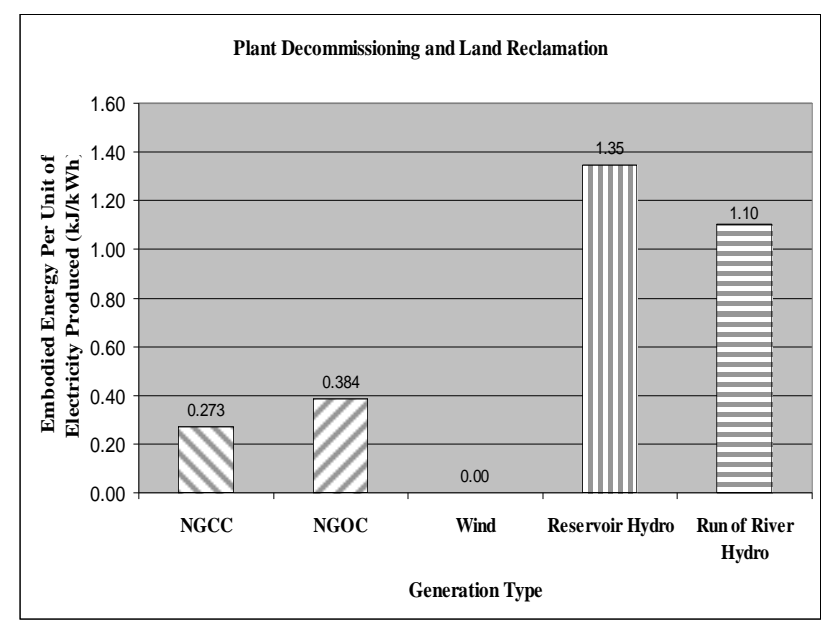

Fig. 5. Normalised Embodied Energies of Plant Decommissioning and Land Reclamation for the Different Generation Methodologies

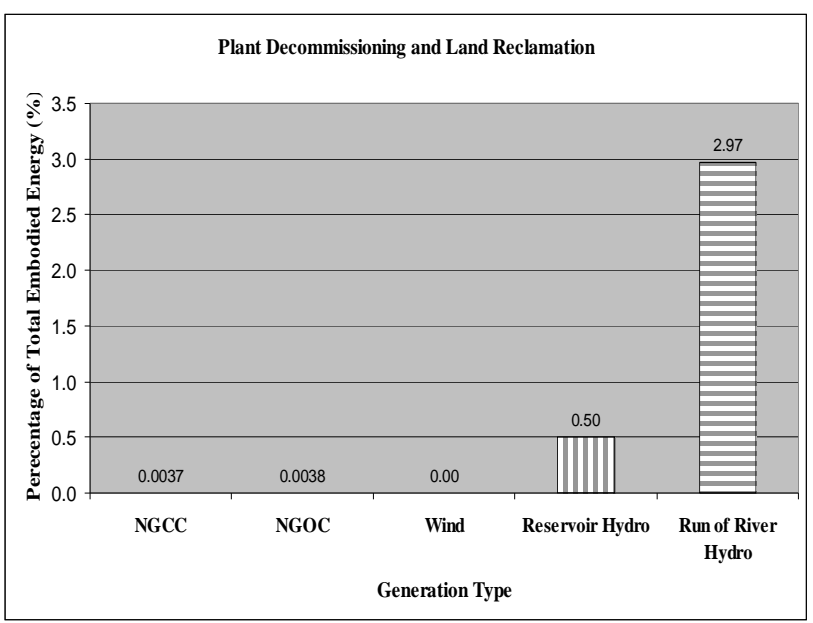

Fig. 6. Proportion of Total Embodied Energy in Plant Decommissioning and Land Reclamation for Different Types of Generation

\subsection{Performance Comparison and Limitations}

The lifecycle electrical outputs normalised over the plant power rating for the different power plants are shown in Figure 7. Generally, the longer the useful life of the plant, the higher the electrical output of the plant normalised over its power rating. The normalised electrical output of the run of river hydro power plant is lower than the reservoir hydro power plant, even though they have equivalent useful lives. This is due to the fact that the run of river hydro plant could never operate at full capacity, because of environmental factors such as droughts and low water levels at its feeding lake, Taupo. Though the above environmental factors would influence the operation of the reservoir hydro power plant, it would not be affected as severely as the run of river hydro power plant because of the large capacity of water stored in the reservoir. The normalised electrical output of the NGCC plant is higher than the NGOC plant because the NGCC plant has a higher thermal efficiency.

The LEPR and the LEC, defined in Equations 1 and 2 for the different power plants, are shown in Table 1. The non- renewable power plants have LEPRs less than unity, whereas the renewable power plants have LEPRs much greater than unity. This is because of the large amount of energy embodied in the fuel input to the non-renewable power plants, without which it would not be possible to produce electricity, whereas in the renewable power plants, electrical energy is produced from flux sources for which there are no energy costs.

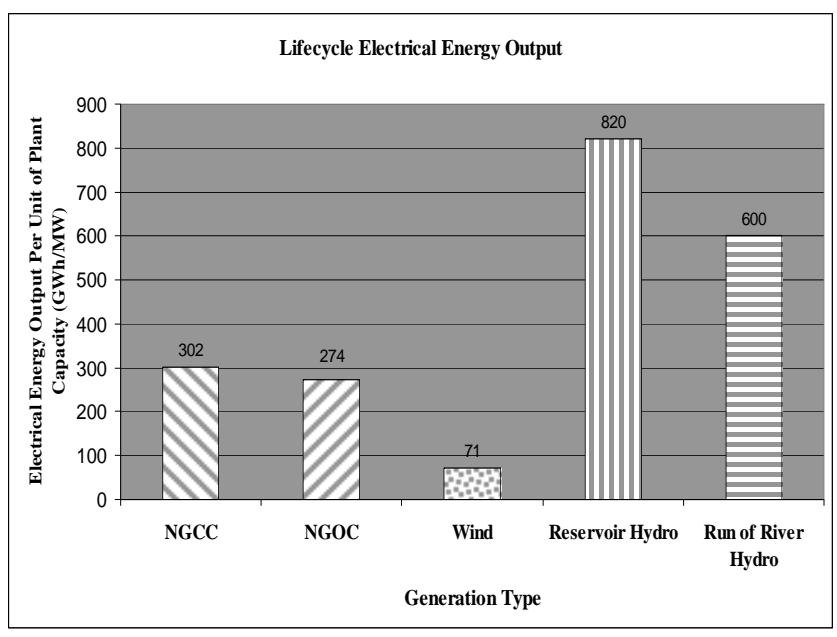

Fig. 7. Lifecycle Electrical Energy Outputs of the Power Plants Normalised Over their Power Ratings

Table 1. LEPRs and Lifecycle Energy Costs of the Different Power

\begin{tabular}{|l|l|l|}
\cline { 2 - 3 } \multicolumn{1}{c|}{} & \multicolumn{1}{c|}{ Plants } & $\begin{array}{l}\boldsymbol{L E C} \\
(\boldsymbol{M J} / \boldsymbol{k} \boldsymbol{W h})\end{array}$ \\
\hline NGCC & 0.487 & 7.39 \\
\hline NGOC & 0.354 & 10.1 \\
\hline Wind & 7.96 & 0.453 \\
\hline Reservoir Hydro & 62.8 & 0.058 \\
\hline Run of River Hydro & 96.9 & 0.051 \\
\hline
\end{tabular}

The hydro power plants have very high LEPRs due to their inherently long useful lives of 200 years, and low energy costs in plant operation and maintenance. The LEPR of the wind power plant of 7.96 is significantly lower than the hydro power plants, because of its lower power rating and very short useful life of just 20 years. The lifecycle efficiency in the NGOC plant is significantly lower than that of the NGCC plant. This is due to the lower thermal operational efficiency of the NGOC plant, as the proportions of total embodied energy in the corresponding lifecycle phases are almost identical in these plants, as illustrated in Figures 2, 4 and 6.

The LECs and LEPRs of the power plants analysed in this paper were compared to the lifecycle performances of other power stations belonging to the same generation methodology. The previous studies used for the comparison were [29], [30] and [22] for the natural gas, wind and hydro power plants respectively. The LEPRs and LECs of the power plants studied in this paper are in 
close proximity to the power plants analysed in the studies mentioned above.

The major limitation when carrying out the analysis was the lack of availability of data. Apart from the Benmore power station, most of the required data for the other power stations were not available. Hence, data from previous studies, most of which are overseas power plants, had to be adjusted to the relevant power stations accordingly. Therefore, some of the data extracted from the overseas power plants might not represent the New Zealand power plants well. For example, the construction data of the wind turbines for White Hill wind farm were extracted from a Danish wind farm which had the same model of wind turbines. Though the wind turbines are of the same model, the wind turbines are constructed slightly differently depending on the location of the wind farm.

The New Zealand I/O energy intensity coefficients were available for only 42 economic sectors, when carrying out the I/O analysis in this study. For all the other sectors, the I/O energy intensity coefficients were estimated from the closest related economic sectors. This might have given an inaccurate approximation of embodied energy for some processes because, even though the items might have similar economic characteristics, this does not necessarily mean that their embodied energies per dollar are alike.

Embodied energy analysis is only a crude method of evaluating greenhouse gas emissions and environmental impacts, and does not provide a complete understanding of the environmental and social impacts of a process. This is true especially for renewable energy generation. For example, reservoir hydro generation has many advantages such as flood control and provision for recreational activities, and disadvantages such as habitat destruction, population displacement and the opportunity loss of land area, including the production of biofuels which addresses carbon emission issues, which are not accounted for in the embodied energy analysis. In the case of wind farms, the land occupied could be used for other economic activities such as sheep farming, whereas in all the other power stations the land cannot be put into other uses.

\section{Conclusion}

Embodied energy is the energy consumed in all activities necessary to support a process in its entire lifecycle. For power generation systems, this includes the energy cost of raw material extraction, transportation, plant construction, energy generation, and the recycling and disposal stages following actual use. Embodied energy analysis is a crude method of estimating the environmental impacts and depletion of natural resources due to a certain process. Essentially, the higher the embodied energy of a process, the greater the GHG emissions and the greater the depletion of natural resources. Also, embodied energy analysis is a useful complement to conventional economic analysis, as it can provide additional information on which to base energy resource allocations.

This paper presents the embodied energy analysis undertaken on some New Zealand power plants belonging to various methods of generation, namely, NGCC, NGOC, wind, reservoir hydro and run of river hydro power plants. The analysis is carried out using a combination of both PCA and I/O analysis. The methodology for the analysis follows the standard set out by the ISO 14040 series, whilst using some useful guidelines given in the IFIAS workshop on energy analysis methodology and conventions.

From the analysis, it was found that for renewable generation power plants, the exploration and plant construction phase of the lifecycle accounts for the largest proportion of the embodied energy. For wind, reservoir hydro and run of river hydro power plants, exploration and plant construction accounted for more than $90 \%$ of the total embodied energy. To improve the lifecycle energy performance of renewable power plants, attention has to be given to the exploration and plant construction phases of the lifecycle.

For non-renewable power plants, the lifecycle phase that accounts for the largest proportion of embodied energy is plant operation and maintenance. For the NGCC and NGOC power plants studied in this paper, plant operation and maintenance accounted for more than $99 \%$ of the total embodied energy of the power plants. This is due to the large measures of energy embodied in the fuel input to the non-renewable power plants. Hence, in order to improve the lifecycle energy performance of nonrenewable energy generation, particular attention has to be given to the plant operation and maintenance phase of the lifecycle, i.e. using turbine/generator systems with higher thermal efficiencies.

The LEPRs of the renewable power plants are greater than unity, whereas the LEPRs of the non-renewable power plants are less than unity. Therefore, in terms of lifecycle energy performance, renewable electricity generation is superior to non-renewable electricity generation. The diverse range of construction methods of hydro power plants, due to environmental and geological aspects, means that these values are not representative of all other hydro power plants. However, the much larger LEPRs of the hydro power plants studied in this paper suggest that the performance of hydro electricity generation is exceptionally higher to other methods of electricity generation.

\section{References}

[1] I. Boustead, \& G.F. Hancock, Handbook of industrial energy analysis (Chichester: Ellis Horwood, 1979). 
[2] G.J. Treloar, R. Fay, \& P.E.D. Love, An analysis of the embodied energy of office buildings by height, Facilities, 19(5/6), 2001, 204-214.

[3] World Energy Council, Comparison of energy systems using life cycle assessment (London: World Energy Council, 2004).

[4] A. Alcorn, Embodied energy coefficients of building materials, $2^{\text {nd }}$ ed. (Wellington, New Zealand: Centre for Building Performance Research. Victoria University of Wellington, 1996).

[5] N.D. Mortimer, Energy analysis of renewable energy sources, Energy Policy, 19(4), 1991, 374-385.

[6] J.A. Alcorn, \& G. Baird, Use of a hybrid energy analysis method for evaluating the embodied energy of building material, Renewable Energy, 8(1-4), 1996, 319322.

[7] A. Alcorn, G. Baird, \& P. Haslam, The energy embodied in building materials - updated New Zealand coefficients and their significance, IPENZ Transaction, 24(1/CE), 1997, 46-54.

[8] B. Norton, P.C. Eames, \& S.N.G. Lo, Full energy chain analysis of greenhouse gas emissions for solar thermal electric power generation systems, Renewable Energy, 15(1-4), 1998, 131-136.

[9] C.W. Bullard, P.S. Penner, \& D.A. Pilati, Net energy analysis: handbook for combining process and inputoutput analysis (Urbana-Champaign, Illinois: University of Illinois, 1976).

[10] International Federation of Institutes for Advanced Study, Energy Analysis, Workshop report no. 6, Stockholm, Sweden, 1974.

[11] International Organisation for Standardisation, AS/NZS ISO 14040: Environmental management - Life cycle assessment - Principles and framework, Standards New Zealand, 1998.

[12] International Organisation for Standardisation, AS/NZS ISO 14041: Environmental management - Life cycle assessment - Goal and scope definition and inventory analysis, Standards New Zealand, 1999.

[13] International Organisation for Standardisation, AS/NZS ISO 14042: Environmental management - Life cycle assessment - Life cycle impact assessment, Standards New Zealand, 2001.

[14] International Organisation for Standardisation, AS/NZS ISO 14043: Environmental management - Life cycle assessment - Life cycle interpretation, Standards New Zealand, 2001.

[15] Genesis Energy Ltd., Huntly power station plants, Retrieved $2^{\text {nd }} \quad$ December, 2009, from http://www.genesisenergy.co.nz/genesis/generation/ourgeneration-sites/huntly-power-station/en/huntly-powerstation-plants.cfm.

[16] T. Halliburton, North Island 400kV Project: Monte Carlo analysis of Auckland area thermal plant availability, Energy Modelling Consultants Ltd., 2005

[17] Genesis Energy Ltd., e3p - Genesis Energy's 385MW CCGT - Huntly Unit 5, Retrieved $20^{\text {th }}$ April, 2009, from http://www.genesisenergy.co.nz/genesis/generation/ourthermal-plants/en/e3p.cfm.
[18] Genesis Energy Ltd., 2007 Annual Report, 2007, (pp10)

[19] Genesis Energy Ltd., Huntly power station, Retrieved $21^{\text {st }} \quad$ April, 2009, from http://www.genesisenergy.co.nz/genesis/generation/ourthermal-plants/en/our-thermal-plants home.cfm.

[20] Meridian Energy Ltd., Discover White Hill Wind Farm, Retrieved $9^{\text {th }}$ January, 2010, from http://www.meridianenergy.co.nz/NR/rdonlyres/B496C00 6-3F64-4F0E-8305C22CAE732A4E/24697/0189MEDWhiteHillWebBro_F Aaj.pdf.

[21] New Zealand Wind Energy Association, White Hill wind farm, Retrieved $9^{\text {th }}$ January, 2010, from http://www.windenergy.org.nz/nz-wind-farms/operatingwind-farms/white-hill.

[22] B.M. Rule, Z.J. Worth, \& C.A. Boyle, Comparison of life cycle carbon dioxide emissions and embodied energy in four renewable electricity generation technologies in New Zealand, Environmental Science 7 Technology, 43(166), 2009, 6406-6413.

[23] Elsam Engineering, Life cycle assessment of offshore and onshore sited wind farms (Denmark: Elsam Engineering, 2004).

[24] Meridian Energy Ltd., Discover Waitaki Hydro Scheme, Retrieved $16^{\text {th }}$ January, 2010, from http://www.meridianenergy.co.nz/NR/rdonlyres/B496C00 6-3F64-4F0E-8305-

C22CAE732A4E/24505/0104MEDWaitakiwebBro12.pdf

[25] A.R. Shearer, Benmore power station (New Zealand Electricity Government Printer, 1975).

[26] Meridian Energy, Embodied energy of White Hill wind farm and Benmore power station, B. Wilson (ed.), Christchurch, 2009.

[27] Mighty River Power Ltd., Aratiatia, Retrieved $28^{\text {th }}$ August, 2009, from

http://www.mightyriverpower.co.nz/Generation/AboutUs/ HydroStations/Aratiatia/Default.aspx.

[28] Electricity Corporation of New Zealand, Waikato: A guide to the Waikato Hydro Group (Wellington, New Zealand: ECNZ Public Relations Group, 1993).

[29] P.J. Meier, Life - cycle assessment of electricity generation systems and applications for climate change policy analysis (Madison, WI: University of Wisconsin, 2002).

[30] M. Lenzen, \& J. Munksgaard, Energy and $\mathrm{CO}_{2}$ lifecycle analyse of wind turbines - Review and applications, Renewable Energy, 26(3), 2002, 339-362. 